\author{
Suely Kofes
}

Universidade Estadual de Campinas

\title{
No labirinto, espadas e novelo de linha: Beauvoir e Haraway, alteridades, e alteridade, na teoria social
}

Resumo: Este artigo contém uma leitura em contraponto: a noção de situação em Simone de Beauvoir e a de intersecções em Donna Haraway expressariam supostos relacionais; mulher estaria para Beauvoir como ciborgue está para Haraway; Beauvoir distingue a situação das mulheres, dos judeus e dos negros, considerando a relação entre situações e consciências históricas e/ou biológicas. A biologia aparece em situação como construção mítica de uma identidade a ser ultrapassada para a constituição do sujeito; em Haraway, o ciborgue seria uma narrativa sobre como o biológico e a realidade social de raça e gênero situam-se em uma rede de interações, informação e semiologia. Relação e constituição do "objeto", temas caros à teoria social, seriam instituídos em (e pela) alteridade sem a dicotomia dura entre realidade e ficção, natureza e cultura, literatura e ciência.

Palovras-chave: Simone de Beauvoir; Donna Haraway; alteridade; teoria social; relação.

Copyright () 2008 by Revista Estudos Feministas.

' Simone BEAUVOIR, 1944, p. 58.

${ }^{2}$ Virginia WOOLF, 1981, p. 109.

${ }^{3}$ Entrevista dada a Philippe Mangeot, Stany Grelet, Victoire Patouillard e Jeanne Revel.

\section{Apresentação}

La beauté de la terre promisse, c'est que elle promettait de nouvelles promesses. ${ }^{1}$

Havia sempre um intervalo entre os atos? Sim, o programa dizia que sim. ${ }^{2}$

Em uma de suas entrevistas, Bourdieu diz que, quando sabemos olhar, as continuidades impressionam mais que as descontinuidades. ${ }^{3}$ Entretanto, não é esse o esforço que farei neste texto ao propor uma leitura em contraponto de Simone de Beauvoir e Donna Haraway. A minha intenção não é traçar diferenças e semelhantes entre as duas autoras; é apenas ler alguns de seus textos com as seguintes indagações: a categoria "mulher" está para 
${ }^{4}$ Um intelectual indiano, com uma formação sólida na teoria social ocidental e interlocutor de todos os seus clássicos. Ver seu depoimento breve na revista L'Homme (Sudipta KAVIRAJ, 2000).

\footnotetext{
${ }^{6}$ A partir principalmente de uma análise do diário de Beauvoir, em Margaret SIMONS, 2002.
}

Simone de Beauvoir como a de "ciborgue" está para Donna Haraway? A noção de "situação" expressa um suposto relacional em Beauvoir tanto quanto a de "intersecções" para Haraway? Nem todas as relações que eu considero importantes serão exploradas, como por exemplo a recusa de ambas à dicotomia entre realidade e ficção, entre literatura e ciência, e os desafios postos a uma teoria social que não se satisfaz com o sociocentrismo - questões diretamente enfrentadas por muitos autores. Entre os quais cabe lembrar Kaviraj ${ }^{4}$ quando se debruça sobre a modernização na Índia e sobre o papel do Estado indiano nesse processo, o que seria dificilmente compreensível com a aplicação das teorias sobre a modernização e formação dos Estados ocidentais sem incorporar a literatura produzida na Î́ndia. Debruçar-se sobre a literatura védica permitiu a esse autor apreender o diferencial de um processo em relação ao ocidental e elaborar uma crítica à dicotomia entre ciências e humanidades. Basicamente, ele conclui que a literatura não constitui uma ameaça ao estatuto de realidade do social e sim uma parceira valiosa para a compreensão de processos tematizados pela teoria social.

Para o presente artigo foi bastante parcial a leitura dos textos das autoras que serão contrapostas: há muitos outros livros, artigos, conferências que precisariam ser lidos, bem como contextualizados. O que se segue, é, portanto, exploratório e inicial.

\section{Explorando textos, lendo mundos conceituais}

\subsection{Singularidade, alteridade, reciprocidade, corpo, situação}

Only the other can create a need for what we give him; all appeal, all demand comes from his freedom; in order for what I have established to appear as good, the other must make it his good: then I am justified in having created it. Only the freedom of the other is able to give necessity to my being. ${ }^{5}$

As leituras mais recentes da obra de Simone de Beauvoir enfatizam a importância de uma interpretação que leve em conta o conjunto de sua obra: a mais estritamente conceitual e filosófica e a ficcional, bem como cartas, diários, autobiografia e memória. Entre as interpretações que resultam dessa leitura, é particularmente destacável a que afirma uma teoria própria de Simone de Beauvoir - uma filosofia propriamente beauvoiriana - e não aquela tradicionalmente atribuída a Sartre. Para Simons, ${ }^{6}$ que sustenta essa tese, uma chave para tal afirmação estaria no tema Outro e no conceito de Situação, como aparecem no diário de 
7 BEAUVOIR, 1949a, tome 2, p. 559.

${ }^{8}$ Diane LAMOUREUX, 1999.

9 LAMOUREUX, 1999.

${ }^{10}$ Françoise RÉTIF, 1999

11 "Libertar a mulher é recusar prendê-la em relações com o homem, mas não negá-las; mesmo que ela se coloque por si mesma, ela não deixará de existir também para ele: reconhecendo-se mutuamente como sujeito, cada um continuará para o outro como um outro" (BEAUVOIR, 1949a, tome 2, p. 559, tradução da editoria).
Beauvoir, de 1927; portanto, dois anos antes de seu encontro com Sartre, conforme sublinha Simons.

Ser sujeito e ser outro para um outro nada tem de irreconciliável. ${ }^{7}$ Esse deslizamento seria mais perceptível quando contrapomos as obras ficcionais de Simone de Beauvoir a $O$ segundo sexo.

Para as duas primeiras autoras citadas, os pressupostos da teoria de Beauvoir, e sua originalidade, estariam em sua concepção de corpo (como território da opressão e um elemento de liberação); para a terceira, na tensão do duplo registro onde se inscreve toda a obra de Beauvoir, a tensão entre a realidade e a utopia. ${ }^{8}$

Também sobre a noção de Outro na filosofia de Beauvoir, Lamoureux ${ }^{9}$ observa como $O$ segundo sexo iniciase pela análise da não-reciprocidade entre os sexos; de fato, da não-reciprocidade de toda relação entre dominantes e dominados, isto é, entre Sujeitos e Outros. Mas para Rétif ${ }^{10}$ o que é importante notar é o deslizamento significativo da autora de Outro (l'Autre), com maiúscula, para outro (l'autre), sem maiúscula, o que separa o começo do fim de $\mathrm{O}$ segundo sexo. No começo desse livro de Beauvoir, o Outro (l'Autre) é aquele que não acede à condição de Sujeito. No último capítulo, "Vers la libération", ser sujeito e ser outro para um outro nada tem de irreconciliável. ${ }^{11}$ Esse deslizamento seria mais perceptível contrapondo-se as obras ficcionais de Simone de Beauvoir ao $O$ segundo sexo e às suas outras obras teóricas. Nas primeiras, conforme Rétif, há uma noção recorrente, a de l'autre en miroir. Isto é, o outro como simultaneamente presente e distante, idêntico e diferente, reunido, mas de forma fugidia, sem fusão. Nas obras ficcionais, como evocação, como representação metafórica, o outro seria considerado o contrário absolutamente irredutível e necessário à realização de um/uma. Para Rétif, portanto, com a noção de l'autre en miroir (l'un et l'autre em face), Beauvoir, distinguindo-se de Sartre, como de toda uma tradição de pensamento, recusaria a fusão ou separação dos contrários e afirmaria a coexistência das diferenças na igualdade. Ou seja, trata-se de outra concepção de outro. Para as duas primeiras autoras citadas, a chave para qualificar os pressupostos da teoria de Beauvoir, e sua originalidade, é a sua concepção de corpo; para a terceira autora, seria a tensão do duplo registro onde se inscreve toda a obra de Beauvoir, a tensão entre a realidade e a utopia. Sobre a concepção de corpo em Beauvoir, diz Diane Lamoureux:

No que concerne ao corpo, encontro um parodoxo na análise de Simone de Beuavoir em $\mathrm{O}$ segundo 
12 LAMOUREUX, 1999, p. 1, tradução minha.

${ }^{13}$ Citada por SIMONS, 2002, p. 45, tradução minha

${ }^{14}$ HOLLAND, 2002. Também sobre esse tema, já explorado exaustivamente, notar estes trechos de uma entrevista com Simone de Beauvoir:

- Você disse em 1967, nas suas conversações com Jeanson: "O feminismo é um modo de viver individualmente e de lutar coletivamente". Viver o feminismo individualmente, como? E lutar coletivamente, como?

- Eu sempre manterei esta fórmula, ou seja, que, individualmente, podemos tentar superar os constrangimentos econômicos que pesam contra as mulheres, podemos tentar ter uma profissão, trabalhar fora, construir uma carreira. No entanto, é perigoso, porque a nossa meta, para nós, para o que chamamos de feminismo radical, não é tomar o lugar dos homens, para cair nos mesmos defeitos que eles. Porque as qualidades singulares que as mulheres podem ter são o resultado de sua opressão: elas não têm esse tipo de rivalidade forçada dos homens, este senso de seriedade, esse sentimento de papel a desempenhar e esse gosto de poder.

[...]

- Desde quando você se define como "feminista radical"? No fundo há não muito tempo?

- Que dizer, eu sempre disse que eu era uma feminista - disse, por exemplo, a Jeanson - na medida em que, feminista, para mim isso quer dizer que eu afirmo uma identidade de situação entre o homem e a mulher, e de igualdade radical entre o homem e a mulher. Mas, como falamos anteriormente sobre o trabalho coletivo, não havia trabalho coletivo feminino que verdadeiramente me interessasse.

É só a partir de 1971 ou 1972 que me encontrei com jovens feministas que me contataram sobre os problemas do aborto, com quem eu comecei a trabalhar, com muita simpatia, pois não eram sexo: ao conceber o corpo como situação, este é considerado simultaneamente como o território da opressão e como um elemento da liberação. ${ }^{12}$

Mas quero sugerir que o conceito de situação em Beauvoir é, principalmente, uma configuração, isto é, relação Sujeito/Outro (em O segundo sexo, também homem/mulher), incorporando opressão ou liberação. Se assim for, não haveria paradoxo e sim um deslocamento interpretativo do corpo para as relações que o formam, ou que criam corporalidade: como Outro para um Sujeito (relação nãorecíproca; imanência; opressão), como outro Sujeito para um Sujeito, singularidade e alteridade (diferença).

Essa interpretação, entretanto, não esgota a complexidade do conceito de situação. Simons destaca uma citação de Beauvoir no livro La force de l'âge, onde ela atribui a originalidade de sua tese em O Segundo Sexo ao seu conceito de situação:

O que distingue a minha tese de uma tese tradicional é que, do meu ponto de vista, a feminilidade não é nem essência nem ntureza: é uma situação criada pelas civilizações a partir de certos dados fisiológicos. ${ }^{13}$

Há mais originalidades em seu trabalho. Eu diria, na linguagem de Haraway, que em $O$ segundo sexo Beauvoir cria uma ficção política, a de mulher. Como a de ciborgue, de Haraway. Ainda que Beauvoir acrescente à sua filosofia uma teoria social na medida em que constitui um novo objeto (mulher), o constrói relacionalmente (em situação), revisa criticamente supostos anteriores ao formular o seu objeto e, intencionalmente ou não, atribui a esse objeto uma condição de sujeito e abre em seu próprio texto um horizonte para a constituição de um sujeito político (ação e consciência). Perguntar-se, como muitos o fazem, se Simone de Beauvoir é ou não feminista (ou se o era quando escreveu tal livro), não é a única nem a mais relevante questão. Embora essa pergunta seja bem enfrentada por Alison T. Holland, ${ }^{14}$ a pergunta que me interessa mais é por que $O$ segundo sexo tornou-se um texto de citação obrigatória em estudos sobre mulheres, gênero, sexualidade e teoria feminista, mas não em referências teóricas mais gerais.

Tem razão Maxime Foerster quando afirma que há duas maneiras de insultar a memória e a obra de Simone de Beauvoir: apresentá-la como a companheira de Jean-Paul Sartre ou saudá-la como uma eminente teórica do feminismo. Embora, diz ele, ambas as afirmações sejam verdadeiras, também constituem uma redução dos escritos beauvoirianos e da unicidade de sua obra, pois a sua filosofia não seria uma cópia do existencialismo satriano, e a sua reflexão sobre a condição das mulheres é mais uma obra importante para 
feministas para tomar o lugar dos homens, mas para mudar o mundo tal como ele é feito pelos homens. E isto é algo muito mais interessante para mim. Não desejamos que as mulheres tomem o gosto do poder e todos os defeitos dos homens. (Entrevista com Simone de Beauvoir realizada por P. Viansson-Ponté Le Monde, 10-11 janvier 1978, $\mathrm{p}$. 1-2, tradução da editoria).

${ }^{15}$ A redução das questões aos objetos precisos recebeu, no caso das sociedades primitivas, no que se refere à antropologia, uma boa crítica de Marc Augé quando este diz: "Teríamos nós partido em direção às culturas diferentes para descobrir o segredo de suas diferenças e explicar o que a economia e a sociologia não explicam? Estaríamos condenados a ter sempre a última palavra, especialistas das flores selvagens da ideologia, do suplemento da alma e da irredutível alteridade dos outros? Se esta tivesse sido nossa ilusão, ela teria rapidamente se esvanecido. O que o etnólogo descobre, à primeira visła, não são culturas, mas sociedades, isto é, conjuntos organizados e hierarquizados onde as noções de diferença e de alteridade têm um sentido" (AUGÉ, 1994, p. 23).

${ }^{16}$ Estou reproduzindo aqui parte de texto que apresentei no seminário temático "Sexualidade, reprodução, parentesco: novas questões, novos desafios. Leituras a partir dos estudos de gênero". Ver Suely KOFES, 2001.

17 Les Temps Modernes, revista mensal, então no seu quinto ano e dirigida por Jean Paul-Sartre.

18 LEVI-STRAUSS, 1949. Cabe ressaltar que Lévi-Strauss, nesse livro, diz que o seu objetivo era uma introdução a uma teoria geral dos sistemas de parentesco. Sem nenhuma concessão ao leigo, dificultando até mesmo para antropólogos não especializados nas tecnicalidades do parentesco, a primeira linha do primeiro parágrafo da primeira edição já se dedica a problematizar o entendimento do conceito de estruturas elementares. uma teoria construtivista do que uma bíblia do feminismo contemporâneo.

Mas apenas uma teoria construtivista? Em O segundo sexo e em Pyrrus et Cinéas, para ater-me apenas a essas duas obras, a alteridade (como relação e diferença, ou diferença em relação) exerce uma função crucial em suas noções de situação e de singularidade, como também nas noções de troca, reciprocidade e ação social.

Em Pyrrus et Cinéas, quando Beauvoir se propõe a definir qual é a minha situação diante de outro (ma situation devant autrui), ela acrescenta que só aí encontraríamos o fundamento para os nossos atos. Explicitamente, refere-se à necessidade que o outro cria para a doação e ao sentido que é criado pelo outro ao que foi doado, o que o torna um bem - lançar-se ao mundo, ato que constitui a existência e que se faz na relação (moi et autrui) e no qual há comunicação, necessidade, justificação e liberdade.

Portanto, existência e ação realizam-se em relação, que não se reduz à interação entre eu e outro, mas ao lugar aberto pelo outro (autrui) à possibilidade de um eu (moi), e que fundaria a situação.

Ao afirmar a necessidade criada pelo outro para a doação e o sentido dado pelo outro ao que foi doado, Beauvoir evoca Marcel Mauss e os seus supostos sobre a troca, embora, para ela, a liberdade no primeiro caso e a obrigação no segundo explicitem a alteridade como condição para a troca e criação da troca. Não estou me referindo à óbvia afirmação de que "para $A$ trocar é preciso $B$ ", mas à alteridade como relação: a troca diferenciando e qualificando outros (valor). Não é o que estaria dizendo Beauvoir sobre a não-reciprocidade e opressão na troca de mulheres pelos homens? Também impossível não evocar algumas das discussões de Sahlins quando situa Mauss, o do Ensaio sobre a dádiva, entre os contratualistas e algumas das reflexões de Paul Ricoeur sobre a relação entre troca e alteridade ${ }^{15}$

Pyrrus et Cinéas foi publicado pela primeira vez em 1944, cinco anos antes de $O$ segundo sexo.

\subsection{Troca como lugar de socialidade $e$ política: reciprocidade, assimetria, opressão ${ }^{16}$}

Em novembro de 1949, no número 49 da revista Les Temps Modernes, ${ }^{17}$ Simone de Beauvoir resenhava o livro recém-publicado Les Structures élémentaires de la parenté, de Claude Lévi-Strauss. ${ }^{18} \mathrm{~A}$ resenha começa dizendo que há muito tempo a sociologia francesa dormia e que era 
19 BEAUVOIR, 1949b, p. 943, tradução minha.
${ }^{20}$ Essa afirmação também pede uma entrada mais minuciosa e interna a algumas das obras críticas à perspectiva de Lévi-Strauss. preciso saudar como um acontecimento o livro de LéviStrauss, "que marca um despertar brilhante" 19

Ela sugere que essa obra criaria um lugar novo para a sociologia francesa, lugar trazido pela etnologia, mas não por isso, e sim porque se apresentava ao mesmo tempo como uma obra científica e especulativa, atenta ao real mas não empiricista.

Uma das questões destacadas por Simone de Beauvoir é sobre os desafios teóricos (e respostas anteriormente dadas) para explicar a proibição do incesto, particularmente em seu caráter de regra e de universal, $O$ que poria em questão a distinção entre natureza e cultura. A explicação de Lévi-Strauss inovaria sobre a relação intrínseca à regra. Ou seja, na leitura de Beauvoir, a regra (relativa ao incesto, proibição e afirmação) integra a oposição entre eu e outro (moi et autrui). Essa relação, cuja realização se dá na troca, seria a condição do social.

A autora destaca que a troca (que fornece substância às relações de reciprocidade) não é entre homens e mulheres, mas entre os homens por meio das mulheres. Sobre este último aspecto, Simone de Beauvoir comenta: existe, sempre existiu, entre os sexos uma profunda assimetria e o "Reino das Mulheres" é um mito desvalorizado.

Se o caráter científico da obra de Lévi-Strauss é realçado, aliás, mais de uma vez, por Simone de Beauvoir, destacam-se três momentos de sua interpretação política dos argumentos do autor.

O primeiro ocorre quando Simone de Beauvoir lembra que a exogamia mostraria que não há sociedade sem 0 reconhecimento de uma regra. Nesse momento, ela tece a sua crítica aos mitos e às mentiras liberais. Ou seja, a intervenção seria constitutiva da humanidade, e não característica de certos regimes econômicos.

O segundo está na referência à troca entre homens por meio das mulheres. Para quem conhece a polêmica de muitas feministas em relação aos argumentos desse livro de Lévi-Strauss, é surpreendente (reconheço expressar um sentimento anacrônico) a sua ausência na resenha de Beauvoir. Não há uma crítica à afirmação de Lévi-Strauss de que as mulheres enquanto signo - ou seja, retendo valor seriam objetos de troca (além daqueles signos na troca econômica e lingüística). O que é afirmado é que tal fato comprovaria a assimetria (considerando o caráter da troca, e através dela a constituição dos parceiros e do que é trocado) constante na relação entre homens e mulheres. ${ }^{20}$

O terceiro momento é quando ela diz que a relação entre o homem e a mulher é também fundamentalmente uma relação com outros homens e com outras mulheres. As relações amorosas e sexuais são acontecimentos íntimos, 
21 BEAUVOIR, 1949a, tome 1, p. 21 , tradução minha.

22 BEAUVOIR, 1949a, tome 1, p 12. mas também públicos, e como tais dizem respeito ao individuo e à sociedade. A sexualidade não seria assim supérflua, nem o seria a preocupação com ela, pois, diz Beauvoir, a maneira pela qual o homem define a sua sexualidade define a sua humanidade.

Em dois parágrafos, já no final, ao aproximar as explicações de Lévi-Strauss ao marxismo, ela também o aproxima ao existencialismo; neste último caso, pela consideração de que a existência humana pressupõe uma relação recíproca com o outro, cuja presença nada teria de acidental. Ora, a exogamia constituiria a presença, e a necessidade, do outro; também, exprimiria e realizaria a transcendência humana e a recusa da imanência.

A argumentação é sinuosa, e mais ainda o é quando nos deslocamos, e bastante bruscamente, da resenha de Beauvoir até agora comentada para uma frase de seu próprio livro:

O proletariado poderia se propor massacrar a classe dirigente; um judeu, um negro, fanáticos, poderiam sonhar adquirir o domínio da bomba atômica e fazer uma humanidade inteiramente judia ou negra. Nem sonhando a mulher pode exterminar os machos. $O$ liame que a une aos seus opressores não é comparável a nenhum outro. A divisão dos sexos é de fato um dado biológico e não um momento da história humana. ${ }^{21}$

\subsection{Mas, não se nasce mulher}

Em O segundo sexo, a descontinuidade entre sociedade humana e natureza (a humanidade não é uma simples espécie natural e o humano se realiza pelo ato de ultrapassar a natureza) é parte substantiva do argumento de Beauvoir. Mesmo referindo-se à distinção de sexos como um dado biológico, ela afirma a não-correspondência entre fêmeas e mulheres (entre femelles et femmes). ${ }^{22}$ Tornar-se mulher, como transcendência e devir - ato e projeto -, remete, simultaneamente, a emancipar-se da natureza, libertar-se da opressão, constituir-se como um Sujeito. Em sua famosa frase "On ne naît pas femme: on le devient", esboça-se a teoria que recusa o biológico como destino; na seguinte frase, logo em seguida, afirma-se um suposto relacional: "Seule la médiation d'autrui peut constituer un individu comme un Autre".

Entretanto, não é suficiente detectar um suposto relacional; é preciso qualificá-lo. Dito de outra forma (o que vale dizer para qualquer teoria que se afirme como relacional), cabe indagar de que relação se trata.

Ao referir-se à mulher como o Outro em relação a um Sujeito, à situação como contendo uma relação entre Sujeito 
${ }^{23}$ BEAUVOIR, 1944, p. 123.

e Outro como não Sujeito, a relação é considerada como não-recíproca, tendo em vista que o poder concentra-se no pólo onde está o sujeito, o que configura a opressão. A emancipação das mulheres como projeto, em Beauvoir, parte da transcendência do destino fisiológico, de uma passagem de fêmea à mulher, do natural ao plenamente humano, e desta mulher em situação para mulher independente.

Ao efetuar uma distinção entre ser categorizado como Outro e tornar-se um Sujeito Outro, caracterizando o segundo como um ato de transcendência (e pelo qual o sujeito se firma como tal), com a segunda formulação, Beauvoir aproxima-se de uma concepção de alteridade como interrupção da ordem (semelhança, totalidade, unidade, exclusão). Ou seja, parece deslocar-se daquela noção domesticada e domesticável de Outro para uma alteridade como resistência ao semelhante (assim: mulher independente \# homem \# mulher-fêmea). Mas, se retomamos Pyrrus et Cinéas, esta última aproximação é limitada ao humano como fronteira.

Há nesse livro um diálogo inicial que instala o dilema sobre a finalidade e a finitude do humano e no qual Cinéas, em sua sabedoria, pergunta a Pyrrus se não seria melhor nem partir para a conquista, já que, depois de todas e tantas batalhas, ele próprio já antevia o seu retorno para a sua casa, para o repouso. Beauvoir dá razão a Pyrrus, e faz um elogio da ação e da escolha. No último parágrafo do livro, ela fala a partir de um nós, livre para transcender e para escapar para outro lugar. A fronteira para a constituição de um nós e para a busca é a condição humana, e é, ao mesmo tempo, limite (para a comparação e para a representação: a quem se comparar senão ao humano? Quem pode falar em seu nome?), fim e perspectiva para o projeto. ${ }^{23}$

Ao sugerir uma teoria social em Beauvoir, na qual há uma reflexão sobre a alteridade (por exemplo, em O segundo sexo, quando ela considera a troca não-recíproca como instituindo a não-igualdade e a opressão, traduzida como criação de diferenças), reconheço também que é justamente na teorização da alteridade que reside um componente que não se reduz ao sociológico. Pois ela não abandona uma concepção de alteridade como categoria da consciência (Sujeito/Outro), a consciência como um atributo humano. Desse ponto de vista, a mulher é para Beauvoir em contraponto aos judeus e negros - o caso-limite, na medida em que a sua opressão não pode ser situada na história nem explicada por razões econômicas. Portanto, parece-me bem compreensível o entusiasmo de Beauvoir com o livro de Lévi-Strauss. Se nesse livro não há brecha para uma teoria sobre a consciência, ele contém uma teoria da troca não redutível à história e aos limites de uma 
${ }^{24}$ HARAWAY, 1992, p. 296.

${ }^{25}$ Embora eu já conhecesse parcialmente a obra de Haraway, a idéia deste trabalho só pôde ser formulada graças às discussões realizadas durante o Seminário Teórico-Metodológico em Ciências Sociais, durante o primeiro semestre de 2003. Compartilhei esse curso oferecido ao Programa de Doutorado em Ciências Sociais com Laymert Garcia e Valeriano Mendes Ferreira Costa. Agradeço, portanto, a eles e aos alunos as leituras e indagações compartilhadas.

${ }^{26}$ MINH-HA, 1986, citada por HARAWAY, 1992.

27 Infelizmente não foi possível incluir as discussões de Donna Haraway publicadas em seu livro ModestWitness@Second_Millennium. FemaleMan(C) Meets_Oncomouse ${ }^{\mathrm{TM}}$, Routledge, 1997, principalmente o seu uso de diffraction, como crítica à reflexão e reflexividade. sociedade - o jogo principal sendo entre humanidade e natureza.

Houve uma leitura literal da categoria "mulher" em O segundo sexo. Estou sugerindo que nesse livro a categoria "mulher" poderia ser equivalente à categoria "sociedade primitiva", uma boa invenção para teorizar a diferença, a particularidade e a opressão. Também, e talvez, Simone de Beauvoir tenha encontrado um melhor operador totêmico para pensar a relação entre a totalidade e a diferença. Afinal, em seus pressupostos, as categorias "fêmea" e "mulher" reúnem relações entre natureza e humanidade, parte e todo. "Mulher" seria, portanto, um operador totêmico mais eficiente porque suposto como relação e como substância.

\section{4. $E$, se nasce ciborgue?}

So, nature is not a physical place to which one can go, nor a treasure to fence in or bank, nor as essence to be saved or violated. Nature is not hidden and so does not need to be unveiled. Nature is not a text to be read in the codes of mathematics and biomedicine. It is not the "other" who offers origin, replenishment, and service. Neither mother, nurse, nor slave, nature is not matrix, resource, or tool for the reproduction of man. Nature is, however, a topos, a place, in the sense of a rhetorician's place or topic for consideration of common themes; nature is, strictly, a commonplace. ${ }^{24}$

Para Donna Haraway a natureza é feita, como fato e como ficção (nature as artifactua). ${ }^{25}$ Organismos não seriam objetos naturais, não nascem, são feitos nas práticas técnicocientíficas em um mundo em mudança, por atores coletivos em tempos e lugares particulares. Mas, diz Haraway, não somos os autores. Se o mundo existe para nós como natureza, ela designa mais uma espécie de relação, uma aquisição de muitos atores, nem todos humanos, nem todos orgânicos, nem todos tecnológicos. Em sua expressão científica, bem como em outras formas, a natureza é feita, mas não inteiramente pelos humanos; é uma co-construção entre humanos e não humanos - articulados, isto é, postos juntos. A fórmula preferida para expressar tal articulação é: a árvore do conhecimento é uma Rede (Web), o que desloca noções como natural, corpo, corpo natural, ser humano, corpo humano, identidade, sujeito/outro e o suposto relacional. Apropriando-se de uma noção de Trinh Minh-ha ${ }^{26}$ - a de inappropriate/d others - Haraway refere-se à procura de uma maneira de figurar a diferença como uma diferença crítica dentro, isto é, diferenças não como marcas especiais para uma taxonomia, mas como intersecções. ${ }^{27}$ Conexões, não classificações.

Concentremo-nos então no Ciborgue, com o qual Donna Haraway não apenas desloca questões como a da 
${ }^{28}$ MENTOR, 1994.

${ }^{29}$ HARAWAY, 1989.

${ }^{30}$ HARAWAY, 1995a.

${ }^{31}$ HARAWAY, 1995b.

${ }^{32}$ HARAWAY, 1995b, p. 277. descontinuidade entre máquinas, humanos e natureza, mas, e principalmente, reage às perspectivas holistas. Conforme Steven Mentor, ${ }^{28}$ em Marx e Marinetti - em O Manifesto Comunista e em O Manifesto Futurista - a tecnologia já aparece como máquina vital; máquina e mundo orgânico são pensados como organismo. Mas, na retórica de Haraway, o ciborgue não remete ao holismo e à necessidade; não supõe um todo, nem um escondido a ser revelado, nem binarismos, mas um produto de sistemas variáveis. No Primate Visions, ${ }^{29}$ Haraway diz que o ciborgue é a interface de automação e autonomia. Em Saberes localizados, ${ }^{30}$ diz a autora que os corpos teriam se convertido em ciborgues, híbridos compostos de encarnação técnicoorgânica e de textualidade. O ciborgue é texto, máquina, corpo e metáfora, teorizados e imersos nas práticas em termos de comunicações.

Em "'Género' para un diccionário marxista: la politica sexual de una palabra", ${ }^{31}$ o ciborgue é um organismo cibernético, um híbrido de máquinas e organismo, uma criatura de realidade social e também de ficção. Não um Eu em relação a um Outro, o ciborgue é um nós, mas o nós é um ciborgue que fratura as identidades. Desconectado de uma raiz, o ciborgue realiza-se pela conexão e pela transgressão de fronteiras. Assim, não é que animal \# humano \# máquina \# animal; a diferença é fusão, entre animal + humano + máquina + animal.

Ou seja, objetos e pessoas podem ser considerados como se fossem desmontáveis ou remontáveis; e nenhuma arquitetura natural impede $o$ desenho do sistema. ${ }^{32}$

Natureza, tecnologia, humano não são ontologias, separadas; são discursivos, narrativos, re-escritos, interrelacionados e re-apresentados. Repetindo Mentor sobre a importância dos supostos de Haraway, "artefacts have politics, technologies can be agents". E que sempre tenha sido assim, conforme John Christie, seria a principal contribuição da autora.

\subsection{Para introduzir um enigma final no contraponto. Ou, e se houvesse continuidade e descontinuldade?}

Beauvoir: L'esprit universel est sans voix, et tout home qui prétend parler en son nom ne faît que lui prêter sa propre voix. Comment pourrait-il prendre le point de vue de l'universel, puisqu'il n'est pas universal?

Haraway: Parte de nuestra reconstrucción como seres humanos socialistas y feministas consiste en rehacer las ciencias que construyen la categoría "naturaleza" e inscribir sus definiciones en la tecnología. ${ }^{33}$ 


\section{Alteridade e/na teoria social}

\footnotetext{
${ }^{34}$ Adam KUPER, 1999.

${ }^{35}$ Conferência dada na University College, Londres.
}

\begin{abstract}
In a sense, it is what we share that produces the differences between us, which in turn depend on our interrelationships. $^{34}$
\end{abstract}

Em maio de 1972, ${ }^{35}$ Mary Douglas citou David Hume sobre a inexistência de necessidade na natureza; esta, conforme ele, seria algo que existe na mente e não nos objetos. A causalidade seria, portanto, uma interpretação da experiência passada; deve-se à força do costume que, ele dizia, estaria bastante abandonado. Para Mary Douglas, o trabalho antropológico seria estudar esses costumes e os diversos mundos verdadeiros que ele constrói, o que implicaria dar razão, embora cautelosamente, a Hume. Em outros autores, diz ela, as teorias causais agrupam-se em duas espécies, as que coincidem com as nossas e não necessitam nenhuma explicação especial e as que são mágicas e estão baseadas em associações subjetivas ou em conveniências mais afetivas que cognitivas quando se tenta distinguir a mentalidade mística da científica. Entretanto, para Hume, todas as teorias causais seriam sensíveis e não cognitivas. Concordando com Hume, Mary Douglas propõe-se a comparar sistemas causais, inclusive os nossos. Sem essa inclusão, e que constitui uma mudança de método, o que resta é a tradução de outras culturas e lógicas às nossas, e a melhor tradução terminaria por evitar qualquer confronto entre sistemas de pensamento mutuamente alheios. Isso manteria o nosso ponto de referência estável a partir do qual outros mundos seriam peculiares e outros tipos de conhecimento seriam deficientes. A tradução prosperaria melhor nos casos de experiência que melhor coincidiriam, mas e quando a tradução fracassa? Quando um novo significado põe à prova e desafia a busca de uma nova expressão, pergunta Mary Douglas?

A falta de coincidência produz o confronto, e o enigma sobre as peculiaridades do pensamento nativo seria um enigma para o pensamento em geral e, inclusive, sobre o nosso próprio pensamento.

A teoria defendida por Mary Douglas é de caráter geral; supõe que, em cada um dos mundos naturais construídos pela sociedade, o contraste entre o que (quem) é homem e o que (quem) não é homem constitui uma analogia do contraste entre o membro da comunidade humana e o estrangeiro. Ou seja, poderíamos dizer, constitui teoria sobre a alteridade.

Estou omitindo boa parte da argumentação de Mary Douglas: sobre a sua sugestão de uma sociologia dos usos da lógica e os exemplos etnográficos com os quais ela vai 
${ }^{36}$ SEGALEN, 1978, p. 20.

buscando as homologias entre maneiras de organizar 0 social e de ordenar o natural e o sobrenatural, tendo em vista a maneira pela qual são tratados as fronteiras, as intersecções e os hibridismos e as anomalias.

A citação de Mary Douglas permitiu-me retomar a sugestão deste artigo situando a concepção de alteridade a que eu me referi e que seria considerada com o sentido que Victor Sengalen dá ao exotismo retomando o sentido de exo, ou seja, o de abrir-se para a busca do que se encontra fora de nossos fatos de consciências atuais, cotidianos, do que não é nossa totalidade mental habitual. ${ }^{36}$ Algo como aqueles incompatíveis que desafiam a tradução, na perspectiva de Mary Douglas.

Finalmente, ao conjugar alteridade e teoria social através do contraponto Simone de Beauvoir e Donna Haraway, quem sabe o enigma proposto no final do contraponto torne compreensível o título completo deste artigo, No labirinto, espadas e novelo de linha: alteridade e/na teoria social.

\section{Referências bibliográficas}

AUGÉ, Marc. Le sens des autres. Paris: Fayard, 1994.

BEAUVOIR, Simone. Pyrrhus et Cinéas. Paris: Gallimard, 1944. . Le deuxième sexe. Paris: Gallimard, 1949a.

"Les structures élémentaires de la parenté, par Claude

Lévi-Strauss". Les Temps Modernes, n. 49, p. 943-949, 1949b.

HARAWAY, Donna. Primate Visions: Gender, Race, and Nature in the World of Modern Science. New York: Routledge, 1989.

. "The Promises of Monsters: A Regenarative Politics for Inappropriate Others." In: GROSBERG, Lawrence, NELSON, Cary, and TREICHLER, Paula (eds.). Cultural Studies. New York: Routledge, 1992. p. 295-337.

. "Saberes localizados: a questão da ciência para o feminismo e o privilégio da perspectiva parcial". Cadernos Pagu, n. 5, p. 7-41, 1995a.

Ciencia, cyborgs y mujeres. La reinvención de la naturaleza. Madrid: Ediciones Cátedra, Universitat de Valencia, Instituto de la Mujer, 1995b.

HOLLAND, Alison T. "Is Simone de Beauvoir a feminist?" In: Simone de Beauvoir and the Women's Movement. Disponível em: http://www.well.ac.uk/cfol/simone.asp. Acesso em: 28 fev. 2002.

KAVIRAJ, Sudipta: "Des avantages d'être un barbare". L'Homme, Revue Française d'Anthropologie, Editions EHESS, n. 156, p. 75-86, 2000. 
KOFES, Suely: "Entre a porta e a ponte. Anotações para uma discussão". In: XXV Encontro Anual da ANPOCS, 2001, Caxambu, MG. Anais... Caxambu, MG: ANPOCS, 2001.

KUPER, Adam. Culture. The Anthropologists' Acount. Cambridge, MA: Harvard University Press, 1999.

LAMOUREUX, Diane. "Le paradoxe du corps chez Simone de Beauvoir”. Labyrinth, v. 1, n. 1, 1999. Disponível em: http:/ /h2hobel.phl.univie.ac.at/ iaf/Labyrinth/Lamoureux.html. Acesso em: 21 fev. 2009

LEVI-STRAUSS, Claude: Les structures élémentaires de la parenté. Paris: Éditions des Presses Universitaires de France, 1949.

MENTOR, Steven. Manifesto Technologies: Marx, Marinetti, Haraway. Disponível em: http://www.converger.com/ cybunny/technohi.htm. Acesso em: jun. 1994.

MINH-HA, Trinh T. "She, the Inappropriate/d Other." Discourse, v. 8, p. 3-43, 1986.

RÉTIF, Françoise: "Modernité de Simone de Beauvoir ou la dialectique d'un engagement". Labyrinth, v. 1, n. 1, 1999. Disponível em: http://h2hobel.phl.univie.ac.at/ iaf/ Labyrinth/retif2.html. Acesso em: 21 fev. 2009.

SEGALEN, Victor. Essai sur l'exotisme, Paris : Le Livre de poche. Biblio essais - 1978.

SIMONS, Margaret A. "L'independance de la pensée philosophique de Simone de Beauvoir". Les Temps Modernes, n. 619, p. 43-52, 2002.

WOOLF, Virginia: Entre os atos. 2. ed. Rio de Janeiro: Nova Fronteira, 1981.

[Recebido em fevereiro de 2008 e aceito para publicação em abril de 2008]

In the Labyrinth, Swords and Thread: Beauvoir and Haraway, Otherness at, and Alterity in, Social Theory

Abstract: In this article I will present a counterpoint between notions of 'situation' by Simone de Beauvoir and 'intersections' by Donna Haraway, which express ideas of relation. I will argue that woman for Beauvoir is like cyborg for Haraway. Beauvoir distinguishes the situation of women, Jews and blacks by considering the relationship between situations and historical consciousness and / or biological weapons. For Beauvoir, the biology in situation appears as construction of a mythical identity to be overcome for the formation of the subject. Alternatively, Haraway uses the cyborg as a narrative of how the biological and social reality of race and gender are into a network of interactions, information and semiology. With this claiming for alterity inside the relation and constitution of the "object", both authors bring important challenges to two of the most important issues of social theory. Moreover, they do it without the hard dichotomy between reality and fiction, nature and culture, literature and science.

Key Words: Simone de Beauvoir; Donna Haraway; alterity; Social Theory; Relation. 